\title{
Anticipation and Exploration of Nature and the Social World: Natural-History versus Social-Cognition Theories of the Evolution of Human Intelligence
}

\author{
Warren D. TenHouten \\ Department of Sociology, University of California, Los Angeles, CA, USA \\ Email: wtenhout@g.ucla.edu
}

How to cite this paper: TenHouten, W. D. (2018). Anticipation and Exploration of Nature and the Social World: Natural-History versus Social-Cognition Theories of the Evolution of Human Intelligence. Sociology Mind, 8, 320-344.

https://doi.org/10.4236/sm.2018.84021

Received: September 21, 2018

Accepted: October 16, 2018

Published: October 19, 2018

Copyright $\odot 2018$ by author and Scientific Research Publishing Inc. This work is licensed under the Creative Commons Attribution International License (CC BY 4.0).

http://creativecommons.org/licenses/by/4.0/

(c) () Open Access

\begin{abstract}
The social-cognition or social-brain theory of human intelligence holds that it is the competitive, hierarchical nature of human society that provided the field of relationality that has fueled the extraordinary development of the human brain and mind. We argue that competitive, agonic society has, in both primates and humans, retarded the development of adaptive intelligence, as evidenced by impressive ethological evidence from primate research. The other kind of sociality, affiliative and hedonic, frees individuals from preoccupation with social hierarchy, but does not motivate anticipatory, goal-seeking behavior. Thus, neither agonic nor hedonic social relations account for human brain evolution, which can rather be attributed to focus on goal-seeking in the natural-history environment, where attention is directed toward exploration, manipulation and utilization of objects, phenomena, and resources. We review ethological evidence from primate and human studies, consider the distinction between fluid intelligence and executive-level functioning, and conclude that the natural-history model appears most consistent with available evidence. Anticipation is described as a primary emotion that develops very early in life, with territoriality as its underlying dimension, and with an elaborate seeking system as its brain infrastructure.
\end{abstract}

\section{Keywords}

Anticipation, Exploration, Social Brain Hypothesis, Natural History Intelligence, Human Evolution

\section{Exploration and Motivation}

In order to understand the extraordinary evolutionary emergence of the human 
brain and mind, it is helpful to review the history of scientific understanding of the concept, exploration. One might presume that the gradual development of the "modern", agentic, individualistic, market-oriented personality would have led to a progressively deeper understanding of exploration as an aspect of human motivation. But this is not at all what happened in the first half of the 20th century under a psychology spanning behaviorism and psychoanalysis. These and related schools of thought recognized only a negative type of motivation, one devoted to the reduction of biological drives, needs, and anxieties. This trend originated in a context of the Darwinian revolution, and of Freud's psychoanalytic theory, according to which mental events are set in motion by unpleasurable tensions which stimulate efforts to re-establish homeostasis. Even the sex drive, a source of pleasurable excitement, was seen as something to be disposed of, as a means to the goal of tension release and the reestablishment of homeostasis. In the extremes of behaviorism, of Watson (1914) and Guthrie (1935), motivation was virtually absent as a topic of concern. Since reinforcers were seen as drive reducers, learning came to be seen as essentially a process of de-motivation. According to stimulus-response (S-R) theory, for example, a rat in a maze would learn nothing, until his response is accompanied by a decrease in hunger or thirst, or by escape from shock (Spence, 1936; Hull, 1943).

Inquisitiveness, and a sense of wonder, is an elaboration of a basic drive to explore the world. McDougall (1928: p. 204) wrote, "emotional-quality [of] wonder accompanies always, in some degree, the impulse or desire to explore and to become better equated with some object... The process of exploration leads to the better comprehension of the nature of the object." Exploratory behavior is most developed in animal species with the most elaborated central nervous systems and brains (Berlyne, 1960: p. 148), finding its highest expression in the human. The Gestalt psychologists (Köhler, 1929; Koffka, 1935; Wertheimer, 1945) contributed to a shift in emphasis from need-reduction to goal-seeking, expectancy, purposiveness, and also to latent learning (Tolman, 1932, 1948; see also Berlyne, 1960: pp. 224-227). In Sociology, Thomas $(1918,1923)$ identified the "wish for new experience" as a fundamental component of social being and as one of four inner force sinters dependent with social cognition and social behavior. Lewin's (1951) influential field theory, which emphasized ego-involvement and striving after success, also helped change the climate by mid-century. After half a century in a behaviorist wilderness of needs-reducing, S-R theorizing, it was rediscovered that, as Koestler (1964: p. 501) asserted, "rats and men are pleasure-seeking creatures, ...some activities are pleasurably self-rewarding, and ... solving a chess problem, or learning to play the guitar are among these activities." Koestler sarcastically described the earth-shattering discovery that rats allowed to familiarize themselves with a maze by running around in it without reward, got to the food quicker when it was later installed than did control rats running the maze for the first time. These rats had been neither rewarded nor punished, yet they had profited from their exploratory behavior (Tolman, 1948). Some, clinging to S-R 
theory, proposed that the gain came from the reduction of curiosity or the drive-reducing diminution of boredom. "One might as well say," Koestler (1964: p. 501) concluded, "that composing a song is a silence-reducing activity."

Even in the darkest days of behaviorism and S-R theorizing, there had been voices in the wilderness, scholars acutely aware that exploration is fundamental for mice and men. McDougall (1923: p. 36), in his principle of self-regard, insisted that striving toward a goal was more satisfying than reaching the goal. Maslow (1943) and Goldstein (1963) both elaborated the similar concept of self-actualization. As Allport (1937: p. 49) put it, "The characteristic feature of such striving is its resistance to equilibrium." Allport argued that psychological unity, and the equilibrium of physiological systems, is attained only as the result of "an active impulse toward growth and self-expression," and it can be attained only as "all of the possibilities of life have been realized" (Allport, 1937: p. 350; see also Allport, 1955: pp. 36-67). Psychiatrists had also come to recognize that, "the normal personality is one that is ever active in pursuit of chosen goals; whereas abnormality is characterized by apathy, by a deficiency in life interests." In the long run, only engagement in projects and productive works confers stability and consistency. Thus, the most unified and stable person is not one who fights off, or finds ways to relieve, tension, but is rather one whose life is characterized by striving, and who gives a strong effort "in becoming what he wants to become" (Allport, 1937: p. 350). Moreover, the attainment of unity depends more upon knowing what we want than upon getting it: "It is the striving toward the known goal that confers unity, not the successful arrival... Attainment may even be destructive of unity, for attainment forthwith abolishes the unifying desire. From this point of view unity lies only in the struggle for unity" (Allport, 1937: p. 350). By the 1950s, it had been well-established, and widely accepted, "that the exploration of novelty, the manipulation of objects, the dismantling and reassembling of complex manual puzzles, and even scribbling and drawing were self-rewarding and self-arousing activities" (Koestler, 1964: p. 504).

Experimental and ethological evidence clearly shows that the urge to explore can prevail even over hunger and fear (Berlyne, 1960: pp. 122-127). Naturalists had known all along that animals are inquisitive and have a basic emotional predisposition to explore and establish control of territorial resources. In the 1930s, it was observed that rats would brave an electrified grill to reach a maze containing only unusual objects. Experiments in which rats were punished for approaching some novel visual patters revealed that, "objects that have become associated with danger are often explored before they are shunned" (Berlyne, 1960: p. 115). Subsequent research revealed that even objects associated with danger were explored; rats and other animals will interrupt their feeding to examine novel objects placed in their environment. Ethologists and psychologists recalled a passage from Darwin's ([1871] 2013: p. 35) Descent of Man, wherein he wrote:

All animals feel wonder, and many exhibit Curiosity. They sometimes suffer from this latter quality, as when the hunter plays antics and thus attracts 
them; I have witnessed this with deer, ... and so it is with some kinds of wild-ducks. Brehm gives a curious account of the instinctive dread which his monkeys exhibited toward snakes; but their curiosity was so great that they could not desist from occasionally satiating their horror in a most human fashion, lifting up the lid of the box in which the snakes were kept.

Inspired by Alfred Brehm's descriptions of animal behavior, Darwin had gone to his local zoo's monkey house, bearing boxes containing a stuffed snake, a dead fish, a mouse, a live turtle, and a live snake in a paper bag. The monkey's reactions to the snake confirmed Brehm's observations, as monkey after monkey peeped into the bag. As for the other items, Darwin exclaimed, "The excitement thus caused was one of the most curious spectacles which I ever beheld," with the turtle causing the greatest level of excitement (Darwin, [1871] 2013: p. 35).

Thus, drive-reduction theories were decisively overthrown, being replaced by the realization that exploratory behavior, which hardly reduces tension, is motivated by a basic emotion-laden drive widely shared in the animal kingdom. There is adaptive value in exploring the environment, understanding and developing cognitive models of it, and thereby being able to anticipate what is apt to happen next. Evidence from throughout the animal kingdom supported this view. Mechanisms underlying exploration and anticipation were revealed by neurophysiological studies by Hebb (1949), Lindsley (1957, 1958), and many others, who shifted the focus from tension-reducing, homeostasis restoring processes in the nervous system and brain to arousing, attention-shaping functions of the midbrain, the reticular activating system, and related systems and structures. Our hunger for new experiences, for novelty, and for exploration, was found to be as basic as the need to satisfy hunger and thirst. Higher animals, and especially humans, spend most of their time in a state of relatively high arousal, eagerly exposing themselves to arousing situations.

As expressed in the world of science and technology, exploration meant control and the ability to predict future states of affairs based on theories and models of physical, biological, and sociocultural systems as they develop and evolve. The ability to predict the future generates an anticipatory intentionality of the mind, based both on emotion and reason, which can be turned into acts, episodes of brief duration, and actions, episodes of longer duration "stretching out into the cared-about futures in an effort to attain objectives, carry out plans, and realize intentions" (TenHouten, 2005: p. 87). Our acts and actions are necessarily based on imperfect judgments and anticipations, so that, in Dewey's (1929: p. 6) terms, "anticipatory uncertainty" means "our actions to be performed can never attain more than a precarious probability," as we head toward an aleatory world that we can see only as a scene of risk and instability. ${ }^{1}$ Our most primordial temporality is based on an anticipatory resoluteness and is futural and ahead

${ }^{1}$ In addition to uncertainty, anticipatory arousal depends on 1) the assessed importance the impending event, 2) the level of surprise one is bracing for, 3) how likely it is that vigorous action not identified beforehand will be required, and 4), how much fear is mixed with anticipation (Berlyne, 1960: p. 185), producing a secondary emotion, anxiety (TenHouten, 2016: pp. 92-93). 
of itself insofar as we not only contemplate the realization of objectives and aims but also imagine the consequences that would follow from success and failure in such striving (Heidegger, 1927). Anticipatory resoluteness is the basis for effort to bring about a cared-about, desired future, which requires various mental processes, of planning, managing, anticipating, monitoring, editing, commanding, controlling, and, more generally, carrying out the executive functions of the brain and mind, and especially in striving to attain long-range goals (Allport, 1955: p. 51). The study of how the brain models the world was clearly framed by Kenneth Craik in The Nature of Explanation, wherein he proposed that the central function of the nervous system is to set up a model of the external world. He wrote that the brain imitates and models external processes, so that "If the organism carries a 'small-scale model' of external reality and of its own possible actions within its head, it is able to carry out various alternatives, conclude which is the best of them, react to future situations before they arise, [and] utilise the knowledge of past events in dealing with the present and future" (Craik, 1943: p. 61).

Thus, an understanding of exploration, and the associated capability to anticipate the future rather than be surprised by it, requires a broad perspective, spanning an appreciation of the role exploratory behavior plays across the animal kingdom, and to its extraordinary further development made possible by the human brain. Exploratory behavior, for humans, is established early in life, and can be observed in the stimulus-seeking behavior of one-year-old children, which occupies them about six hours per day. This play is ontogenetically adaptive because it enables developing children (and young non-human animals) to alter their relationships to the natural environment, thereby "enriching" the environment, endowing it with things of value, seeing it as replete with resources, and learning how to incorporate and utilize these resources (Schore, 1994: pp. 95-98).

\section{Natural History and Social-Cognition Intelligence}

The general consensus in primatology (e.g., Flynn, Geary, \& Ward, 2005) and social neuroscience (see, e.g., Adolphs, 2002) is that the ability to carry out complex social relationships successfully selects for intelligence. This social-cognition theory asserts that "social integration and intelligence probably evolved together, reinforcing each other in an ever-increasing spiral" (Jolly, 1966: p. 504), that the "chief role of creative intellect is to hold society together" (Humphrey, 1976: p. 307), and that status-striving within social groups develops reasoning abilities (de Waal, 1982). This theoretical position emphasizes that the status-strivings of individuals within groups involves political maneuvering and develops reasoning abilities. Thus, the social-cognition model, or the social-brain hypothesis (Dunbar, 2002), is essentially a theory of Machiavellian intelligence, which sees a focus on social relationships, including deceit, trickery, manipulation, and interpersonal competition (de Waal, 1982: p. 74; Byrne \& 
Whiten, 1988; Byrne, 1995). ${ }^{2}$ The social-cognition intelligence theory emphasizes that certain kinds of social behavior, such as exploitation and deception, at the expense of others, such as tolerance and behavioral coordination (Barrett \& Henzi, 2005). This theory holds that-as a consequence of living in permanent social groups with local competition for scarce resources-the pressure is on individual members to evolve an ability to "outwit" other group members, which would alleviate the negative effects of competition on social success and, in turn, can stimulate counter-strategies.

Non-human primate cognition is widely believed to be based on social relationships and characterized by Machiavellian intelligence (Cheney, Seyfarth, \& Smuts, 1986; Cheney \& Seyfarth, 1990; Whiten \& Byrne, 1997). Proponents of the Machiavellian-intelligence hypothesis have focused on our closest relative, the chimpanzee. According to the what Cachel derisively calls the "chimpocentric" mind-set, chimp sociality is sees as the ne plus ultra of the animal world (Beck, 1980). Cachel (2006: pp. 373-374), a self-described apostate from the social-brain hypothesis, points out that the most complex primate sociality is not found in chimpanzees, bonobos, or other pongids, but rather in New World marmosets and tamarins (callitrichid platyrrhimes). They are the only non-human primates ranked as eusocial, that is, as truly social, using the standard three-part sociobiological definition: 1) cooperation in care of their young; 2) a reproductive division of labor, and 3) overlap of two or more generations contributing to social life (Wilson, 1975). Their intricate social behaviors include: communal caring for the young; the provisioning of infants and juveniles with high-energy foods; monitoring, managing, and extracting gum and resin food resources; and complex vocal communication (Snowdon, 1982; Savage \& Baker, 1996). If the social cognition model was correct, it would be expected that our closest relatives, the chimpanzees and the bonobos, would be eusocial, but this is not the case.

While the great apes are more intelligent than are monkeys, there is little evidence that the social cognition of great apes differs much from that of monkeys (Tomasello \& Call, 1997). Chance (1988: pp. 3-7) has argued that this kind of intelligence, which he associates with competitive, "agonic" social relationships, is more characteristic of monkeys than it is of apes. While wild chimpanzees are able to understand something of the goals, intentions, and desires of conspecifics, they do not appear to share with humans a theory of mind which would enable them to understand that others might be focused on other objects in the same visual field, or to comprehend a wide array of psychological states understood easily by human children (Cachel, 2006: p. 154). Not recognizing false beliefs, they understand each other in terms of a perception-goal psychology rather than a human-like belief-desire psychology (Call \& Tomasello, 2008). Moreover,

${ }^{2}$ The ideas of Machiavellian manipulation as a source of human brain evolution has been downplayed by certain social-cognition theorists, who argue instead that it was selection pressure for large but cohesive social groups together with the evolution of language in human evolution that caused increase in relative neocortex size (Dunbar, 1992; Aiello \& Dunbar, 1993; Harari, 2015). 
domestic dogs clearly outperform chimpanzees in using social cognition to interact with humans in cooperative tasks (Hare \& Tomasello, 2005).

Especially damaging to the social-cognition theory of the origins of human intelligence are studies of monkeys, which plainly show that their preoccupation with the social order, especially with social-dominance hierarchy, leads to a neglect of the natural world, such that predators go unnoticed. Particularly telling is an intensive study of vervet monkeys (Cercopithecus aethiops) carried out at the Amboseli Reserve in Kenya (Cheney \& Seyfarth, 1990). These monkeys were found to be highly knowledgeable about social dynamics, yet they show a limited awareness of the natural world. Vervet mortality was high, estimated at 65 percent in 1987, with leopards accounting for about 70 percent of these vervet deaths. Yet this predation was not associated with awareness of predator behavior. These vervets did not associate carcasses cached in trees with leopard presence, even though they possess a specific alarm call for leopards. Pythons are another of their predators, yet they seemed not to link python tracks to python presence. When experiments played recorded hippopotamus and black-winged stilt calls from inappropriate dry woodland habitats, they made no response. Thus, in spite of their social awareness, vervet monkeys appear to be largely unaware of much of their external environment and, as Cachel (2006: p. 165) put it, "peculiarly obtuse or stupid about making associations and predictions about the external world, sometimes despite intense positive selection pressure for them to do so."

\section{Tool Usage}

Experiments with tool use in captive hamadryas baboons and pig-tailed macaques appear to demonstrate that social dynamics involving status and sexual behavior hinder tool behavior (Beck, 1980). Experiments with tool use in captive tufted capuchin monkeys, whose tool behavior in the wild is the most pronounced among non-human primates, also repeated demonstrate minimal ability of animals in a social group to acquire tool use through imitation, although imitation of social behavior occurs (Visalberghi, 1993).

Attention to natural history is far more developed in the human than in any other species, to the point that this kind of fluid intelligence can be identified as very possibly the single most important factor in the tripling of brain size now manifested in contemporary humans (Cachel, 2006: p. 155). Cachel describes the complex behaviors which have necessitated such attention to the environment. The first stone tools, of the Oldowan stone tool industry, are to be found in the Pliocene of East Africa, dating back to 2.6 - 2.5 million years ago (mya). The archaeological record becomes much denser and variable about 200,000 years later, and involved transportation of stones and carcasses, stone tools, alteration of animal bones, and knowledge of the behavioral ecology of other species, including interactions with sympatric carnivore species (Cachel \& Harris, 1995). The availability of raw materials for stone tool manufacture, Cachel proposes, 
could have been a crucial resource for hominids, and might well have profoundly affected ranging and foraging behavior. "Complex foraging for dispersed resources implies intimate knowledge of the regional environment, and the ability to locate and predict the abundance of resources which have fluctuated widely in space and time. These complex behaviors necessitated an attention to natural history, which appears documented at an ancient date" (Cachel, 2006: p. 155).

Far later in time, about 40,000 years ago, in the European Upper Paleolithic, both portable and parietal artistic productions reveal the attention of its creators to fine details of the morphology and behavior of non-human animals (Klein, 1989). By 12,000 - 13,000 years ago, humans had developed awareness of ontogenetic processes within other species, together with symbolic manipulation of this awareness, of the birth, growth, behaviors, and death of members of other species. To this, Cachel (2006: p. 156) adds: "With the advent of a written record of human thought, there is undeniable evidence of human attention to, and manipulation of, the external environment."

\section{Intelligence}

Cachel's theory of natural history intelligence holds that the remarkable tripling of the size of human brains relative to other hominids began at least as far back as 2.5 mya. Cachel does not separate technical intelligence (e.g., for tool behavior) and natural history intelligence (for understanding the physical and biological worlds). Her argument is that complex interactions with biological and physical factors demand behavioral flexibility based on an integration of data from multiple senses. This flexibility has been enabled by elaborate organization of the neuroanatomical pathways which organize attention. The ability to understand what is happening in the environment includes the anticipating, planning for, and monitoring events. "As a consequence," Cachel (2006: p. 159) infers, "natural history intelligence by itself contributes to the formation of a general or fluid intelligence by expanding attentiveness and awareness away from the tyranny of the social world, which generates the social intelligence identifiable in non-human primates."

Natural history intelligence can be linked to fluid, or general intelligence, on the grounds that both emphasize planning, manipulating, and predicting processes and events in the non-social environment. These factors together add up to a model of the world beyond the social group and social relationships, which requires the creation of symbol systems for the manipulation of, and anticipation of events in, the external environment (Cachel, 2006: pp. 146-184). While natural history intelligence exists to some extent in non-human primates, and vertebrate species in general, it finds fullest expression in humans. The weight of evidence suggests it is natural history intelligence-which is not well-developed in primate species, even those most closely related to humans-which has vaulted the human so far beyond other primate species that is has been historically difficult for human beings to accept the simple fact that we 
are, after all, animals, and more specifically, apes. Human capabilities for habitual tool behavior, material and symbolic culture, control of the environment, knowledge and control of other species, and a keen interest in the secrets of nature, all largely result from the emergence of natural history intelligence.

Immersion in the social might well have impeded development of natural history intelligence. Competitive social behaviors, including all kinds of social striving for success and high status consumes attention and limits awareness to what is happening socially, thereby locking the mind into a present gestalt of the social world. Consider an example. While high-ranking female monkeys launch randomly timed attacks on subordinates in order to induce in them insecurity and stress, it hardly creates the conditions for exploration of the world or even for vigilance with respect to territorial boundaries and the risk posed by would-be predators (Chance, 1988; Cachel, 2006). Social dominance hierarchies are inherently unstable and can come with great costs to the community at large and to members at all levels of a social hierarchy. It is only when the social organization of a species of animals gets beyond such hypersociality that natural history intelligence can co-evolve with neuroanatomical substrates able to direct awareness and attention to the world beyond and outside of the social group. This situation is prerequisite for the development of complex, symbolic models of the world which can then be subjected to abstract manipulated.

Our potential territory is the natural history environment, and exploration of territory and space is a fundamental problem of life (Plutchik, 1962, 1980). For humans, freed from preoccupation with social hierarchy, it has become possible to develop a systematic methodology for investigating the physical world, the biological world, and even the social world. This methodology, in a word, is science. Beginning about 2.5 mya, the ancestors of today's humans came to awareness of, and paid attention to, vegetable species beyond the realm of everyday foraging, the morphology and behavior of other animal species, and of kinds of rocks and woods. This development of the brain and mind was a first effort to generalize, to classify, to recognize patterns and processes, to generate rules about the regularities of nature, to anticipate events, and to plan behaviors intended to lead to the control of events and processes. As Cachel (2006: p. 160) asserts, "This intelligence functions in cognitive problems that involve anticipating properties of objects outside the social world, once the object is recognized as possessing certain other properties, or being able to reason about cause and effect in the world outside the social group."

Cachel (2006: p. 160) further observes that "[s]ome developmental psychologists have recently argued that learning in human infants and children is organized precisely like scientific learning through data collection and hypothesis-testing." As might be expected, efforts have been made to compare the scientific reasoning of humans to the "folk psychology" of chimpanzees, which refers to the way they understand the material world, with emphasis on their knowledge of energy, movement, objects, and object interactions. While humans and 
chimps share the same sensory systems, only humans can deal with unobservable, hypothetical phenomena and spatial relationships (Povinelli et al., 2000; Povinelli \& Vonk, 2003). After nearly a century of research on the mentality of apes-which has been motivated by a desire to show that humans are not unique-surprisingly has led to a renewed appreciation of the uniqueness of the human mind and brain. It has been an implicit assumption of the Machiavellian intelligence theory that social intelligence is transferable to other spheres. It is the opposite of this assertion which appears to be the case, for the methodology of science can indeed be, and has been, applied to the social world, as is evidence by the emergence of fields of scientific study such as anthropology, sociology, political science, economics, and the other less general fields of social-scientific inquiry, such as management science, operations research, and game theory.

Cachel (2006: p. 157, 159) equates natural history intelligence with "fluid" intelligence, and with Spearman's general intelligence (the $g$ factor, the intelligence quotient'). While some researchers resist the idea of a general intelligence which can be applied across cognitive domains, $g$ does appear to have a basis in brain functioning. For example, studies of human twins show that the quantity of frontal-lobe gray matter is under significant genetic control, and that gray-matter quantity is positively related to measure of $g$ (Thompson et al., 2001). When subjects brains were scanned (using positron emission tomography) while engaging in tasks requiring high $g$, there was localized frontal lobe activation (Duncan et al., 2000).

\subsection{Intelligence and Executive Functioning}

While some early investigators saw the frontal lobes as the "seat of intelligence", contemporary studies have demonstrated that significant levels of frontal damage do not reduce performance on conventional intelligence tests (Milner, 1964; Roca et al., 2009). Yet these individuals are unable to organize everyday activities, and are inflexible and not inventive in their approach to new problems. They are deficient in divergent thinking, e.g., in listing various uses of a given object, and lack verbal fluency. They become confused about the temporal order of recent and remote events, which contributes to their inability to anticipate, and to plan for the future (Milner, Petrides, \& Smith, 1985).

While frontal damage leaves cognitive performance relatively conserved in a computational sense, it is the "same person" that comes up missing (Gardner, 1993: p. 261, Goldberg, 2001). If orbital portions of the frontal lobes are damaged, the result is apt to be irritability, hyperactivity, insouciance, or euphoria. If the higher regions (convexity) of the frontal lobes sustain injury, the more likely result is indifference, listlessness, slowness, apathy, and a kind of depression. Consider Luria's (1972) report on the case of "the man with the shattered world." Zasetsky, a young Soviet soldier in World War II, had suffered a severe wound of the left parietal-occipital area, which crippled his ability to carry out intellectual and cognitive functions: his speech was crippled, he could not write, 
hammer a nail, or carry out a simple chore. His general intelligence, $g$, had been devastated. Yet, he retained his personhood, his will, his desires, his sensitivity to experiences, and the ability to form plans and endeavor to carry them out. With his frontal lobes intact, he had remained the same person.

\subsection{Two Pathologies: Autism and Williams' Syndrome}

We cannot accept the view that the divorce between social and natural history intelligences, which might have been important in the evolutionary development of the human brain, is permanent. In fact, a divorce on occasion is not final, for there can be reconciliation and remarriage. And this might well have happened in human evolution. The effective human mind must have proficiency in modeling both the natural environment and the social world. To see that this is true, we can examine cases in which people are pathologically limited to one domain. With Cachel (2006: pp. 172-173), we can look at social intelligence in the absence of history intelligence, and at natural history intelligence in the absence of social intelligence. Both are well-known pathologies-those of autism and Williams' syndrome, respectively, each of which have a strong genetic substrate (Riby \& Hancock, 2008).

Autistic individuals interact freely with the non-living world, the world of natural history, and are apt to be highly competent with mathematics and mechanics. Many with autistic spectrum disorder are able to easily memorize trivia, and show superior skills of attending and perceiving, and have intact connectivity of task-positive brain networks involved in sustained attention and goal-directed thinking (Broyd et al., 2009). In several studies, it has been found that autistics have a clear preference for nonsocial over social stimuli (Jeste \& Nelson, 2009).

On the negative side, autistics develop only limited social skills, as indicated by paying little attention to social stimuli, not making eye contact with others, and experience difficulty understanding and communicating, both verbally and nonverbally, with others. They are limited in their ability to access the minds, motives, and emotions of their fellow humans (Hall, 2017), are lacking in social intelligence (Baron-Cohen et al., 1999), and are limited in the expression and recognition of emotion displayed by others (Rodier, 2000). Individuals suffering from this neurodevelopmental disorder are impaired in their social behavior, as they tend not to develop appropriate sociorelational behaviors such as turn-taking and making and maintaining friendships, and are possibly prone to aggression, property destruction, and tantrums.

Individuals suffering from Williams' syndrome manifest an opposite orientation. Affected individuals are charming and facile in social communication, being gregarious and skilled in social conversations in parties and engage effectively in "small talk". ngage effectively in ked cytoskeletal defects to Williams syndrome. BioEssays 26: 141-150.They have outgoing personalities, interact readily with strangers, are socially disinhibited, and are often hyperfocused on the 
eyes of others in social situations. They can recognize emotions expressed by others, and themselves produce speech rich in prosody and emotional description (Kaplan, Wang, \& Francke, 2001). In social interactions, they are not aggressive, and show empathy, kindness, unselfishness, and forgiveness (Tager-Flusberg \& Sullivan, 2000).

On the other hand, Williams' Syndrome individuals are handicapped in their meager understanding of the natural world. As children, they were slow to make use of tools, to classify objects, and to see how objects are related to each other. They are show to develop understanding of the temporal processes of birth, growth, and death. As adults, they are impaired in spatial relationships and direction finding, having difficulty orienting themselves spatially, in moving about even in their own neighborhood (Bellugi, Wang, \& Jernigan, 1994). They experience lack of acuity in basic visuospatial problem solving (Atkinson et al., 2001).

It would appear that the normal condition of the human brain and mind is one in which there is social competence, which involves insight into the motives, intentions, and feelings of other persons, or the development of a "theory of mind" providing adequate understanding of the likely mental state and focus of awareness of other persons. Also required for a normal human existence is an orientation to one's potential territory and the resources available in the environment. Required here is a kind of natural history intelligence, so that the plants, animals, and inanimate objects of the world are seen as related to each other as an integrated whole. Of course, competence in both domains, the social and the non-social, does not mean that both be attended to and focused on at the same time.

\section{Anticipation and Its Brain Infrastructure, the Seeking System}

Given the adaptive priority of future planning, we find it helpful to think of the brain as a fundamentally prospective organ that is designed to use information from the past and present to generate predictions about the future-Schacter, Addis, \& Buckner (2007: p. 660).

\subsection{Anticipation as Emotion and Cognition}

Early in infancy, conscious mental experience is primarily a function of drive signals, indicating distress or pleasure in response to inner events and processes, and to interest in the external world. Izard (1980: p. 203; see also Izard, 2009) notes that, "In early infancy ... the emotion of interest is present, and it serves to focus and maintain attention to sources of external stimulation. Interest-sustaining attention ... is essential in attaining percepts and in learning to discriminate objects and persons."As the child develops, this instinct for taking interest develops into a more complex capability for anticipatory planning for action, in being able to change a course of action once it has begun, and to prepare options and strategies to deal with cognitive models of what might happen. 
Anticipation, and its opposite, surprise, have been considered by some researchers not to be emotions, primarily on the ground that they have a substantial cognitive content (Ortony \& Turner, 1990: p. 317). Indeed they do. Piaget (1971: p. 57) correctly viewed anticipation as both affective and cognitive, describing it as "one of the most generally found characteristics of the cognitive function. Anticipation dawns as soon as perception dawns." Piaget (1971: p. 57) distinguished between instincts, "a vast system of surprising kinds of anticipation, which seem to be unconscious, while the inferences of thought promoteanticipation of a conscious kind," arguing that most biological functions are also anticipations.

There is a close linkage between exploration of the environment, seeking resources and things of value, and anticipation. Exploration of the environment leads to the development of anticipation, which was observed by Pavlov in his description of a "signalizing" reflex as anticipatory or preparatory to motor attitudes (see Bull, 1951). Plutchik's $(1962,1980)$ psychoevolutionary theory of the emotion identifies territoriality as one of four basic problems of life widespread in the animal kingdom, along with identity, temporality, and hierarchy. The basic functions of territoriality are exploration and boundary-defense, which call forth the adaptive reactions of anticipation and surprise, respectively (Plutchik, 1962; see also TenHouten, 2017).

While exploration-anticipation has emotional content, it also has a cognitive aspect. For if we are to adapt to the world by focusing only on the immediate present, we risk survival. What is needed to both survive and prosper is a viable model of the world, such that many happenings and processes can be foreseen by the exercise of thought. Thus, anticipation derives from a capacity for inference based on previously acquired and remembered, and thereby conserved, information, which is embedded in a schemata, a model, of the world. Piaget argued that conservation of information previously acquired enables anticipatory reactions on the cognitive level, so that an essential function of knowing is to bring about foresight. The establishment of any scientific law presupposes such foresight, for experiments can be designed to have certain predictions, or expectations, of results. Because such a law pertains to the future as well as the present and the past, it not only permits foresight, but makes it necessary. While this anticipatory function is intrinsic to science, it also exists in everyday life, on the levels of elementary habits and even of perception. This view is consistent with Tolman's (1948) learning theory, which sees every sensorimotor organization oriented to expectations of future events, even when they are based on "sign gestalts" or significant configurations, for these significations are always relative to expectations.

From Piaget's (1971) perspective, the function of anticipation is one of the most generalized in organic life, because it is an extension of all forms of conserved information, whether inherited or acquired. Conservation, which is necessary to all forms of organization, is extended in anticipation. Anticipation, 
seen in this way, can be characterized causally as the outcome of the transfer or generalization of information previously organized in schemata and preserved throughout the process of development. Much of our ability to anticipate is genetically inherited, and to this extent we are guided by pre-established genetic information which is nonetheless anticipatory because it adjusts behavior to the external environment, "as though it has both knowledge of the end in view and instrumental relationships subordinating to this end a series of successive and connected mean in a soundly adaptive manner" (Piaget, 1971: p. 197). ${ }^{3}$

The human brain (and mind) is an anticipatory device (Castelfranchi, 2005; Pezzulo \& Castelfranchi, 2007). The mind is organized to anticipate, build, and work on internal representations of the world, not of current perceptions, but a "simulation" of perception which enables anticipation of upcoming stimuli, or of effects of a cause, or of a possible action to be taken. This, Miceli and Castelfranchi (2015: p. 3) assert, "precisely is intelligence: not the mere ability to exhibit complex adaptive behaviors..., but the ability to solve a problem by working on an internal representation of the problem, by acting up 'images', 'schemata', or mental models, by simulating events and actions and by anticipating possible solutions." The main purpose of the human brain, then, is "to produce a future" (Dennett, 1991: p. 177).

\subsection{The Seeking System}

A mental state of anticipation comes about as an individual is motivated to attain a goal or secure a resource in the environment. The prefrontal cortex organizes anticipatory behavior in a top-down way by activating thalamo-cortical loops involving sensory and motor areas, so that motor areas become set to implement action intended to attain a goal or secure a resource (Brunia, 1999). A slow-wave potential, Stimulus-Preceding Negativity (SPN), has been identified as preceding four types of stimuli: 1) stimuli providing knowledge of results of past goal-directed activity; 2) stimuli conveying instructions, tactics and strategy about a future endeavor; 3 ) stimuli against which the outcome of a previous objective has to be matched; and 4) stimuli that activate emotion and feeling in a way that encourages engagement in goal-directed behavior (for a review, see van Boxtel \& Böcker, 2004), which involves insular brain activation (Simons, Öhman, \& Lang, 1979).

Panksepp (1998: pp. 144-163; see also Alcaro \& Panksepp, 2011; Panksepp \& Biven, 2012: pp. 95-144) describes the role of hormones in anticipatory and appetitive behavior, noting that the desires and aspirations of the human being, while not attributable to a single brain system, come to a dramatic standstill if certain brain systems, such as the dopamine (DA) circuit generated from midbrain nuclei, are destroyed. A person thus rendered unable to "partake of worldly

\footnotetext{
${ }^{3}$ The function of anticipation-exploration indeed enables adaptation to the world, but by imagining future objects, conditions, situations, and arrangements, the anticipatory function further enables willfully changing of the world, of adapting the world to human needs and desires through construction of artifacts and sociocultural organization.
} 
delights" can "achieve the feelings of success" in infusion of L-DOPA, the precursor of DA (Panksepp, 1998: p. 144). Both animals and humans can operate smoothly and effectively in their daily pursuits only if the ascending DA tracts are functioning properly. Without these tracts, it is not possible to be engaged in, and excited about, seeking the necessities of life and the cognitive-affective interests "that bring positive existential meanings to our lives" (Panksepp, 1998: p. 144). Without DA, human aspirations to success in life "remain frozen, as it were, in an endless winter of discontent". Panksepp refers to the brain's DA systems, which are emotional circuits, the "foraging/exploring/investigation/curiosity/interest/expectancy/SEEKING" system (Panksepp, 1998: p. 144).

Panksepp argues that the humans striving for necessities and goals is motivated by the welling up of ancient neurochemistry in primitive parts of the brain. These neurochemicals stimulate animals, including humans, to investigate and explore the world, to seek resources, and to understand the natural history environment. While Cachel refers to the role of the "executive brain" in her analysis of the evolution of the human mind, Panksepp (1998: p. 145) looks to the Seeking System (SS), which leads organisms to "eagerly pursue the fruits of the environment-from nuts to knowledge, so to speak." This emotional system-which provides the psychic energy of exploration, anticipation, and expectation-has a characteristic feeling tone "akin to that invigorated feeling of anticipation we experience when we actively seek thrills and other rewards" (Panksepp, 1998: p. 145).

The basic circuits for this intrinsic brain function are concentrated in the extended lateral hypothalamic corridor. This system deals with emotions, but also with somatic feelings, because it responds to homeostatic imbalances, that is, to bodily need states and to perceived environmental incentives. This system spontaneously learns about environmental events which predict the availability of resources, although it remains unclear how reinforcement processes are able to do this. But Panksepp is convinced that these trans-hypothalamic circuits are at the heart of the SS. As key evidence, he observes that the lateral hypothalamus (LH) continuum, running from the ventral tagmental area to the nucleus accumbens, is the brain area where electrical stimulation promptly evokes energized exploratory and search behaviors. The brain DA circuits correspond to the general trajectory of this psychobehavioral system. It follows that the basic impulse to search, investigate, and understand the environment emerges from the circuits of the LH. Brain DA is essential in operatingcuits of the L-H. The brain DA circuits correspond to the general trajectory of this psychobehavioral syste these circuits, although many other chemicals are also involved.

Panksepp's SS is a general incentive or appetitive motivational system which mediates not liking but wanting. This neuroemotional system, the basis of the emotion exploration-anticipation, drives and energizes many mental complexities which people express as feelings of interest and, if cognition is very highly developed, the search for higher meanings. While this system is initially without 
any cognitive content, it helps us understand causal connection, in the environment and thereby contributes to the creation of ideas, theories, and more generally of the fundamentals of culture, including the key developments of language and writing. The SS provides the aspirational desire for creations, but the actual realization of creations further requires logically coherent thought together with intentionality (TenHouten, 1994, 2011).

The affective state associated with the SS is not what we feel in consummatory behavior. Instead, "it resembles the energization organisms apparently feel when they anticipate rewards" (Panksepp, 1998: p. 146, emphasis added). The SSis initially activated by cues of rewards, such as sights and smells. Panksepp (1998) suggests that such cues attain control through glutamate circuits from the cortex, hippocampus, and striatal areas such as the thalamic nuclei, which descend onto the SS, which then anticipates rewards (Taber, Das, \& Fibiger, 1995). The SShas been linked to several emotions. Panksepp, for his part, links arousal of this system to "intense interest," "engaged curiosity," and "eager anticipation." His terminology is entirely consistent with emotion theory, which identifies a primary emotion whose function is "exploration" and whose subjective terms are "expectation" and "anticipation" (Plutchik, 1962: pp. 102-107). The affective expression of interest is clear and evident in young infants. When the LH is stimulated, individuals do not report sensory pleasure of a consummatory kind but rather a feeling that something very interesting and exciting is going on (Quaade, Vaernet, \& Larsson, 1974). When we consummate behavior and are satiated-as in the cases of food, water, sex, more generally the attainment of a goal, the SS is deactivated.

Panksepp presents a compelling argument that the SS circuits are indeed associated with a basic emotional system. With Plutchik's psychoevolutionary emotions theory, affect-spectrum theory (TenHouten, 2007, 2013, 2017) claims anticipation is a primary emotion, and because several emotions researchers have been convinced otherwise (e.g., Ekman, 1980), it is informative to outline Panksepp's six-part argument that exploration, interest, and anticipation comprise a basic emotional state. He presents six arguments, briefly summarized here:

1) "The underlying circuits are genetically prewired and designed to respond unconditionally to stimuli arising from major life-challenging circumstances" (Panksepp, 1998: p. 150). Anticipation is most certain not entirely cognitive, as has been argued by some, for the SS continues to function effectively in animals even after their higher cognitive mechanisms are surgically removed. The survival value of this function, Panksepp adds, is indicated by the fact that damage along its trajectory reduces the chances of survival more than it does if damage occurs at a later age.

2) "The circuits organize behavior by activating or inhibiting motor subroutines (and concurrent autonomic-hormonal changes) that have proved adaptive in the face of life-challenging circumstances during the evolutionary history of the species" (Panksepp, 1998: p. 150). Moreover, the mesolimbic/cortical DA 
circuits, at the heart of the SS, enable animals, and humans, to perform motivated, goal-seeking behaviors. Stimulation invigorates this system; damage disables it.

3) "Emotive circuits change the sensitivities of sensory systems relevant for the behavior sequences that have been aroused" (Panksepp, 1998: p. 150). Studies indicate that unilateral electrical arousal of the SS leads to more effective cortical processing. Thus, the anticipation of a goal sharpens the reasoning involved in attaining this goal. This clearly shows a productive interaction between rational cognition and the emotion anticipation. Such electrical stimulation also increases the metabolic processes of the aroused side of the brain, including cortical areas.

4) "Neural activity of emotive systems outlasts the precipitating circumstances" (Panksepp, 1998: p. 150).

5) "Emotive circuits can come under the conditional control of emotionally neutral environmental stimuli" (Panksepp, 1998: p. 150). The SS is capable of spontaneous learning, as shown by single-cell activity during simple forms of appetitive condition, and in the anticipatory shaping of unconditional response systems, such as the exploratory sniffing of a rat during brain stimulation. Ventral tegmental DA cells have been found to exhibit anticipatory learning during appetitive conditions, and the DA system vigorously releases DA during the anticipatory phase of a behavioral sequence.

6) "Emotive circuits have reciprocal interactions with brain mechanisms that elaborate higher decision-making processes and consciousness" (Panksepp, 1998: p. 150). It has been found that mild stimulation of the SS results in a pleasant form of energy, which stimulates individuals to pursue various interests and life-sustaining activities. This has been documented in Parkinson's patients treated with L-DOPA. The result was an temporary awakening from their prior state of "suspended animation" to an experience of life's vibrancy, and to a positive, interest-filled engagement with the world (Sacks, 1973).

\section{Discussion and Conclusions}

If the human brain has evolved largely out of the necessity of understanding the natural history environment, a fundamental question arises: Out there, in the environment, what did our pre-human ancestors and humans in the foraging and hunting phase of social evolution most need to understand? The answer is obvious, and "primitive" people will remind us, if we would but listen: The non-human animals. Any why are these animals so important? The answer is simple: Only by understanding the habits and behaviors of animals, and being therefore to anticipate their movements and actions, could we successfully kill and then eat them (and avoid being eaten by them). For this, early humans needed an ecological theory of mind, with which they could peer into the minds of animals. Abrams (1997: p. 86) notes, "We find ourselves alive in a listening, speaking world." Here, language is expanded in its meaning, as all animals and 
natural forms speak their own dialect, and all species have the power of language, in the sense of communication: "Just as a human may suddenly understand the subtle gestures of a deer, or the guttural speech of a raven, so the other entities hear, and may understand, our own talk."

Without guns and gunpowder, a native hunter, to be successful, must come close to his prey if he is to take away its life. Physical proximity is required, but, as Abrams (1997: p. 140) further observes, this closeness must also be

emotional, empathically entering into proximity with other animals' ways of sensing and experiencing. The native hunter, in effect, must apprentice himself to those animals he would kill. Through long and careful observation, the hunter gradually develops an instinctive knowledge of its habits, of its fears and its pleasures, its preferred foods and favorite haunts. Nothing is more integral to this practice than learning the communicative signs, gestures, and cries of the local animals.

The skilled hunter will learn to generate, and mimic the vocalizations of these animals, and this capability "enables him to enter most directly into the society of other animals" (Abrams, 1997: p. 141). This level of natural-history intelligence is not to be found within the social dynamics of human community, either in its agonic or hedonic aspects, but in an understanding of the enveloping ecosystem and the natural environment.

Hunted animals, of course, wish to survive, and to this end pay careful attention to the humans who would hunt them. This is what Merleau-Ponty (1962) called "perceptual reciprocity," as a listening to the forest is also, primordial, to feel oneself listened to by the forest. To gaze at the surrounding forest is to feel oneself exposed and visible, to feel oneself watched. For foraging people, then, survival requires careful attention to the behavior of the natural surroundings, watching and integrating the living world's gestures. While we strive to anticipate the whereabouts of our prey animals, they are cognizant of our movements, our talking, our intentions. Prey animals will develop tactics to deceive the hunter, to confound his efforts to approach closely enough to kill them. Thus empathy, in the sense of having insight into what other persons and animals are thinking and feeling (but not necessarily in the sense of responding with sensitivity and caring), both for the hunter and the hunted, is an affect-laden mental capability of great evolutionary significance.

The linkage between exploration of the environment and hunting, that is, the anticipatory nature of capture (and escape), is on the level of perception elaborated by Berthoz (2000: p. 165; see also Bernstein, 1967), who shows that planning a motor activity requires exploration of the future, which necessarily involves recognizing patterns of what will be but do not yet exist. This is true both of a frog catching a fly (or avoiding a hawk), a tennis play anticipating the speed and trajectory of an incoming ball, and a human hunter anticipating the arrival of a deer at a pond. As Berthoz (2000: p. 164) explains, "Perception is active exploration; it is a question put to the world, a wager, pre-selection-it is also cap- 
ture. Consider gaze. Visual perception is possible only by actively exploring the environment through gazing enabled by movements of the eyes... Each gaze cast constitutes capture, especially if the object of regard is in motion. This capture is anticipatory, predictive."

Anticipatory behavior, then, involves "a temporary combining of Past and Future, for which the momentary situation is the point of departure. Such anticipatory behavior "implies plans for action," such that "[e]ach action is aimed at a goal. Preparation of an action implies the foreseeing of the consequences of the crucial event that will trigger the action. In other words, the preparation is based upon a view from the future... [which is] based upon past experience" (Brunia, 1999: p. 214). Were we to try to adapt to the world by focusing only on the immediate present, we would not survive for long. We need a model of the world that foresees, predicts, and anticipates happenings and processes. Anticipation is no mere fusion of past and present, for the present, as explained by Albert North Whitehead (1920: p. 69, 191), has thickness, with its early boundary "blurred by and fading into memory and it's later boundary..., blurred by an emergence from anticipation," such that "[t]here is no sharp distinction either between memory and the present immediacy and anticipation." Goal-directed, fluid intelligence is required when individuals face environmental challenges that require adaptive reactions which include conscious anticipation, an understanding of what is happening in the environment, together with a grasp of the likely consequences of various courses of action (Roca et al., 2009). This requires a mental representation, a model, of the sensed, perceived, and emotionally cared about world, which comes from the interaction of perception, thought, and intention. The amazing human brain has developed not as a result of a capability to outwit conspecifics in the struggle for positions and prerogatives in social dominance hierarchies, as claimed by social-brain theorists, but rather by understanding, and thereby gaining control of, the larger world of life and of physical nature.

\section{Conflicts of Interest}

The author declares no conflicts of interest regarding the publication of this paper.

\section{References}

Abrams, D. (1997). The Spell of the Sensuous: Perception and Language in a More-than-Human World. New York: Vintage Books.

Adolphs, R. (2002). Social Cognition and the Human Brain. In J. T. Cacioppo, G. G. Berntson, R. Adolphs, et al. (Eds.) Foundations in Social Neuroscience (pp. 69-87). Cambridge, MA: The MIT Press.

Aiello, L. C., \& Dunbar, R. I. M. (1993). Neocortex Size, Group Size, and the Evolution of Language. Current Anthropology, 34, 184-193. https://www.jstor.org/stable/2743982 https://doi.org/10.1086/204160

Alcaro, A., \& Panksepp, J. (2011). The SEEKING Mind: Primal Neuro-Affective Substrates for Appetitive Incentive States and Their Pathological Dynamics in Addictions 
and Depression. Neuroscience and Biobehavioral Reviews, 35, 1805-1820. https://doi.org/10.1016/j.neubiorev.2011.03.002

Allport, G. W. (1937). Personality: A Psychological Interpretation. New York: Holt, Rinehart, \& Winston.

Allport, G. W. (1955). Becoming: Basic Considerations for a Psychology of Personality. New Haven, CT: Yale University Press.

Atkinson, J., Anker, S., Braddick, O., Nokes, L., Mason, A., \& Braddick, F. (2001). Visual and Visuospatial Development in Young Children with Williams Syndrome. Developmental Medicine \& Child Neurology, 43, 330-337.

https://doi.org/10.1017/S0012162201000615

Baron-Cohen, S., Ring, H. A., Wheelwright, S., Bullmore, E. T., Brammer, M. J., Simmons, A., \& Williams, S. C. R. (1999). Social Intelligence in the Normal and Autistic Brain: An fMRI Study. European Journal of Neuroscience, 11, 1891-1898.

Barrett, L., \& Henzi, P. (2005). The Social Nature of Primate Cognition. Proceedings of the Royal Society B: Biological Science, 272, 1865-1875.

https://doi.org/10.1098/rspb.2005.3200

Beck, B. B. (1980). Animal Tool Behavior. New York: Garland Press.

Bellugi, U., Wang, P. P., \& Jernigan, T. L. (1994). Williams Syndrome: An Unusual Neuropsychological Profile. In S. H. Broman \& J. Grafman (Eds.), Atypical Cognitive Deficits in Developmental Disorders: Implications for Brain Function (pp. 23-56). Hillsdale, NJ: Lawrence Erlbaum.

Berlyne, D. E. (1960). Conflict, Arousal, and Curiosity. New York: McGraw-Hill Book Company. https://doi.org/10.1037/11164-000

Bernstein, N. A. (1967). The Coordination and Regulation of Movement. New York: Pergamon Press.

Berthoz, A. (2000). The Brain's Sense of Movement. Cambridge, MA: Harvard University Press.

Broyd, S. J., Demanuele, C., Debener, S., Helps, S. K., James, C. J., \& Sonuga-Barke, E. J. (2009). Default-Mode Brain Dysfunction in Mental Disorders: A Systematic Review. Neuroscience and Biobehavioral Review, 33, 279-296. https://doi.org/10.1016/j.neubiorev.2008.09.002

Brunia, C. H. M. (1999). Neural Aspects of Anticipatory Behavior. Acta Psychologica, 101, 213-242. https://doi.org/10.1016/S0001-6918(99)00006-2

Bull, N. (1951). The Attitude Theory of Emotion. New York, NY: Nervous and Mental Disease Monographs.

Byrne, R. (1995). The Thinking Ape: The Evolutionary Origins of Intelligence. Oxford: Oxford University Press. https://doi.org/10.1093/acprof:oso/9780198522652.001.0001

Byrne, R., \& Whiten, A. (1988). Machiavellian Intelligence: Social Expertise and the Evolution of Intellect in Monkeys, Apes, and Humans. Oxford: Clarendon Press.

Cachel, S. (2006). Primate and Human Evolution. New York, NY: Cambridge University Press.

Cachel, S., \& Harris, J. W. K. (1995). Ranging Patterns, Land Use, and Subsistence in Homo Erectus from the Perspective of Evolutionary Ecology. In J. R. F. Bower, \& S. Sartono (Eds.), Proceedings of the Pitheanthropus Centennial, 1893-1993; Vol. I, Palaeoanthropology: Evolution and Ecology of Homo Erectus (pp. 51-66). Leiden: Leiden University Press.

Call, J., \& Tomasello, M. (2008). Does the Chimpanzee Have a Theory of Mind? 30 Years 
Later. Trends in Cognitive Science, 12, 187-192.

https://doi.org/10.1016/j.tics.2008.02.010

Castelfranchi, C. (2005). Mind as an Anticipatory Device: For a Theory of Expectations. In M. De Gregario, V. Di Maio, M. Frucci, \& C. Musio (Eds.), Brain, Vision, and Artificial Intelligence (pp. 258-276). Berlin: Springer. https://doi.org/10.1007/11565123_26

Chance, M. R. A. (1988). Introduction. In M. R. A Chance (Ed.), Social Fabrics of the Mind (pp. 1-35). Hillsdale, NJ: Lawrence Erlbaum.

Cheney, D. L., \& Seyfarth, R. (1990). How Monkeys See the World. Chicago, IL: University of Chicago Press.

Cheney, D. L., Seyfarth, R., \& Smuts, B. B. (1986). Social Relationships and Social Cognition in Nonhuman Primates. Science, 234, 1361-1366. https://doi.org/10.1126/science.3538419

Craik, K. J. W. (1943). The Nature of Explanation. Cambridge: Cambridge University Press.

Darwin, C. (2013). The Descent of Man and Selection in Relation to Sex. London: Wordsworth.

Dennett, D. C. (1991). Consciousness Explained. Boston, MA: Little \& Brown.

de Waal, F. B. M. (1982). Chimpanzee Politics: Power and Sex among Apes. New York, NY: Harper \& Row.

Dewey, J. (1929). The Quest for Certainty. New York, NY: Minton, Balch and Company.

Dunbar, R. I. M. (1992). Neocortex Size as a Constraint on Group Size in Primates. Journal of Human Evolution, 22, 469-493. https://doi.org/10.1016/0047-2484(92)90081-J

Dunbar, R. I. M. (2002). The Social Brain Hypothesis. In J. T. Cacioppo, G. G. Berntson, R. Adolphs et al. (Eds.), Foundations in Social Neuroscience (pp. 69-87). Cambridge, MA: The MIT Press.

Duncan, J., Seitz, R. J., Kolodny, J., Bor, D., Herzog, H., Ahmed, A., Newell, F. N., \& Emslie, H. (2000). A Neural Basis for General Intelligence. Science, 289, 457-460. https://doi.org/10.1126/science.289.5478.457

Ekman, P. (1980). The Face of Man: Expressions of Universal Emotions in a New Guinea Village. New York, NY: Garland STPM Press.

Flynn, M. V., Geary, D. C., \& Ward, C. V. (2005). Ecological Dominance, Social Competition, and Coalitionary Arms Races: Why Humans Evolved Extraordinary Intelligence. Evolution and Human Behavior, 26, 10-46. https://doi.org/10.1016/j.evolhumbehav.2004.08.005

Gardner, H. E. (1993). Multiple Intelligences: The Theory in Practice. New York, NY: Basic Books.

Goldberg, E. (2001). The Executive Brain: Frontal Lobes and the Civilized Mind. Oxford: Oxford University Press.

Goldstein, K. (1963). Human Nature in the Light of Psychopathology. New York, NY: Schocken Books.

Guthrie, E. R. (1935). The Psychology of Learning. New York, NY: Harper \& Row.

Hall, L. J. (2017). Autism Spectrum Disorders: From Theory to Practice (3rd ed.). New York, NY: Pearson.

Harari, Y. N. (2015). Sapiens: A Brief History of Humankind. New York, NY: HarperCollins. 
Hare, B., \& Tomasello, M. (2005). Human-Like Social Skills in Dogs. Trends in Cognitive Science, 9, 439-444. https://doi.org/10.1016/j.tics.2005.07.003

Hebb, R. G. (1949). The Organization of Behavior. New York, NY: Wiley.

Heidegger, M. (1927). Being and Time (J. Macquarrie \& E. Robinson Trans.). Oxford: Blackwell.

Hull, C. L. (1943). Principles of Behavior: An Introduction to Behavior Theory. New York, NY: Appleton-Century-Crofts.

Humphrey, N. K. (1976). The Social Function of Intellect. In P. G. Bateson, \& R. A. Hinde (Eds.), Growing Points in Ethology (pp. 303-317). Cambridge: Cambridge University Press.

Izard, C. E. (1980). The Emergence of the Emotions and the Development of Consciousness in Infants. In J. M. Davidson, \& R. J. Davidson (Eds.), The Psychobiology of Consciousness (pp. 193-216), New York, NY: Plenum Press. https://doi.org/10.1007/978-1-4684-3456-9_9

Izard, C. E. (2009). Emotion Theory and Research: Highlights, Unanswered Questions, and Emerging Issues. Annual Review of Psychology, 60, 1-25. https://doi.org/10.1146/annurev.psych.60.110707.163539

Jeste, S. S., \& Nelson, C. A. (2009). Event Related Potentials in the Understanding of Autism Spectrum Disorders: An Analytical Review. Journal of Autism and Developmental Disorders, 39, 495-510. https://doi.org/10.1007/s10803-008-0652-9

Jolly, A. (1966). Lemur Social Behavior and Primate Intelligence. Science, 153, 501-506. https://doi.org/10.1126/science.153.3735.501

Kaplan, P., Wang, P. P., \& Francke, U. (2001). Williams (Williams Beuren) Syndrome: A Distinct Neurobehavioral Disorder. Journal of Child Neurology, 16, 177-190. https://doi.org/10.1177/088307380101600305

Klein, R. G. (1989). Biological and Behavioral Perspectives on Modern Human Origins in South Africa. In P. Mellars, \& C. Stringer (Eds.), The Human Revolution (pp. 530-546). Edinburgh: Edinburgh University Press.

Koestler, A. (1964). The Act of Creation. New York, NY: Penguin Books.

Koffka, K. (1935). Principles of Gestalt Psychology. New York, NY: Harcourt, Brace and Company.

Köhler, W. (1929). Gestalt Psychology. New York, NY: H. Liveright.

Lewin, K. (1951). Field Theory in Social Science. New York, NY: Harper.

Lindsley, D. (1957). Psychophysiology and Motivation. In M. R. Jones (Ed.), Nebraska Symposium on Motivation (pp. 44-105). Lincoln: University of Nebraska Press.

Lindsley, D. (1958). The Reticular System and Perceptual Discrimination. In H. H. Jasper (Ed.), International Symposium on Reticular Formation of the Brain (pp. 513-534). Boston, MA: Little, Brown.

Luria, A. R. (1972). The Man with a Shattered World: The History of a Brain Wound. New York, NY: Basic Books.

Maslow, A. H. (1943). A Theory of Human Motivation. Psychological Review, 50, 370-396. https://doi.org/10.1037/h0054346

McDougall, W. (1923). An Outline of Psychology. London: Methuen \& Co. Ltd.

McDougall, W. (1928). Emotion and Feeling Distinguished. In Feelings and Emotions: The Wittenberg Symposium (pp. 200-205). Worcester, MA: Clark University Press.

Merleau-Ponty, M. (1962). Phenomenology of Perception. New York, NY: Humanities Press. 
Miceli, M., \& Castelfranchi, C. (2015). Expectancy and Emotion. Oxford: Oxford University Press.

Milner, B. (1964). Some Cognitive Effects of Frontal-Lobe Lesions in Man. Philosophical Transactions of the Royal Society of London. Series B: Papers of a Biological Character, 298, 211-226.

Milner, B., Petrides, M., \& Smith, M. L. (1985). Frontal Lobes and the Temporal Organization of Memory. Human Neurobiology, 4, 137-142.

Ortony, A., \& Turner, T. J. (1990). What's Basic about Basic Emotions? Psychological Review, 97, 315-331. https://doi.org/10.1037/0033-295X.97.3.315

Panksepp, J. (1998). Affective Neuroscience: The Foundations of Human and Animal Emotions. New York, NY: Oxford University Press.

Panksepp, J., \& Biven, L. (2012). The Archaeology of Mind: Neuroevolutionary Origins of Human Emotions. New York, NY: W. W. Norton \& Company.

Pezzulo, G., \& Castelfranchi, C. (2007). The Symbol Detachment Problem. Cognitive Processing, 8, 115-131. https://doi.org/10.1007/s10339-007-0164-0

Piaget, J. (1971). Biology and Knowledge: An Essay on the Relations between Organic Regulations and Cognitive Processes. Chicago, IL: University of Chicago Press.

Plutchik, R. (1962). The Emotions: Facts, Theories, and a New Model (Revised ed.). Lanham, NJ: American Universities Press.

Plutchik, R. (1980). Emotion: A Psychoevolutionary Synthesis. New York, NY: Harper \& Row.

Povinelli, D. J., Reaux, J. E., Theall, L. A., \& Giambrone, S. (2000). Field Physics for Apes: The Chimpanzee's Theory of How the World Works. Oxford: Oxford University Press.

Povinelli, D. J., \& Vonk, J. (2003). Chimpanzee Minds: Suspiciously Human? Trends in Cognitive Science, 7, 157-160. https://doi.org/10.1016/S1364-6613(03)00053-6

Quaade, F., Vaernet, K., \& Larsson, S. (1974). Stereotaxic Stimulation and Electrocoagulation of the Lateral Hypothalamus in Obese Humans. Acta Neurochirurgica, 30, 111-117. https://doi.org/10.1007/BF01405759

Riby, D. M., \& Hancock, P. J. B. (2008). Viewing It Differently: Social Scene Perception in Williams Syndrome and Autism. Neuropsychologia, 46, 2855-2860. https://doi.org/10.1016/j.neuropsychologia.2008.05.003

Roca, M., Parr, A., Thompson, R., Woolgar, A., Torralva, T., Antoun, N., Mans, F., \& Duncan, J. (2009). Executive Functions and Fluid Intelligence after Frontal Lobe Lesions. Brain, 133, 234-247. https://doi.org/10.1093/brain/awp269

Rodier, P. M. (2000). The Early Origins of Autism. Scientific American, 282, 56-63. https://doi.org/10.1038/scientificamerican0200-56

Sacks, O. (1973). Awakenings. New York, NY: Dutton.

Savage, A., \& Baker, A. J. (1996). Callitrichid Social Structure and Mating Systems: Evidence from Field Studies. American Journal of Primatology, 38, 381-383. https://doi.org/10.1002/(SICI)1098-2345(1996)38:1<1::AID-AJP1>3.0.CO;2-2

Schacter, D. L., Addis, D. R., \& Buckner, R. L. (2007). Remembering the Past to Imagine the Future: The Prospective Brain. Nature Reviews Neuroscience, 8, 657-661. https://doi.org/10.1038/nrn2213

Schore, A. N. (1994). Affect Regulation and the Origin of the Self: The Neurobiology of Emotional Development. Hove: Lawrence Erlbaum Associates.

Simons, R. F., Öhman, A., \& Lang, P. J. (1979). Anticipation and Response Set: Cortical, 
Cardiac, and Electrodermal Correlates. Psychophysiology, 16, 222-233. https://doi.org/10.1111/j.1469-8986.1979.tb02982.x

Snowdon, C. T. (1982). Linguistic and Psycholinguistic Approaches to Primate Communication. In C. T. Snowdon, C. H. Brown, \& M. R. Petersen (Eds.), Primate Communication (pp. 212-238). Cambridge: Cambridge University Press.

Spence, K. W. (1936). The Nature of Discriminant Learning in Animals. Psychological Review, 43, 427-429. https://doi.org/10.1037/h0056975

Taber, M. T., Das, S., \& Fibiger, H. C. (1995). Cortical Regulation of Subcortical Dopamine Release: Mediation via the Ventral Tegmental Area. Journal of Neurochemistry, 65, 1407-1410. https://doi.org/10.1046/j.1471-4159.1995.65031407.x

Tager-Flusberg, H., \& Sullivan, K. (2000). A Componential View of Theory of Mind: Evidence from Williams Syndrome. Cognition, 76, 59-90. https://doi.org/10.1016/S0010-0277(00)00069-X

TenHouten, W. D. (1994). Creativity, Intentionality, and Alexithymia: A Graphological Analysis of Split-Brained Patients and Normal Controls. In M. P. Shaw, \& M. A. Runco (Eds.), Creativity and Affect (pp. 225-257). Norwood, NJ: Ablex Publishing Corporation.

TenHouten, W. D. (2005). Time and Society. Albany, NY: State University of New York Press.

TenHouten, W. D. (2007). A General Theory of Emotions and Social Life. London: Routledge.

TenHouten, W. D. (2011). Handwriting and Creativity. In M. A. Runco, \& S. R. Pritzker (Eds.), Encyclopedia of Creativity (pp. 588-594, Vol. 1, 2nd ed.). San Diego, CA: Academic Press.

TenHouten, W. D. (2013). Emotion and Reason: Mind, Brain, and the Social Domains of Work and Love. London: Routledge.

TenHouten, W. D. (2016). The Emotions of Powerlessness. Journal of Political Power, 9, 83-121. https://doi.org/10.1080/2158379X.2016.1149308

TenHouten, W. D. (2017). From Primary Emotions to the Spectrum of Affect: An Evolutionary Neurosociology of the Emotions. In A. Ibáñez, L. Sedeño, \& A. M. Garcia (Eds.), Neuroscience and Social Science: The Missing Link (pp. 141-167). New York, NY: Springer. https://doi.org/10.1007/978-3-319-68421-5_7

Thomas, W. I. (1918). The Polish Peasant in Europe and America; Monograph on an Immigrant Group (Vol. 3). London: Forgotten Books.

Thomas, W. I. (1923). Chapter 1: The Wishes. In W. I. Thomas (Ed.), The Unadjusted Girl with Cases and Standpoint for Behavior Analysis (pp. 1-40). Boston: Little Brown and Company.

Thompson, P. M., Cannon, T. D., Narr, K. L., van Erp, T., Poutanen., V. P., Huttunen, M., Lönnqvist, J., Standertskjöld-Nordenstam, C. G., Kaprio, J., Khaledy, M., Dail, R., Zoumalan, C. I., \& Toga, A. W. (2001). Genetic Influences on Brain Structure. Nature Neuroscience, 4, 1253-1258. https://doi.org/10.1038/nn758

Tolman, E. C. (1932). Purposive Behavior in Animals and Men. New York, NY: Century.

Tolman, E. C. (1948). Cognitive Maps in Rats and Men. Psychological Review, 55, 189-208. https://doi.org/10.1037/h0061626

Tomasello, M., \& Call, J. (1997). Social Cognition of Monkeys and Apes. Yearbook of Physical Anthropology, 37, 273-305. https://doi.org/10.1002/ajpa.1330370610

Van Boxtel, G. J. M., \& Böcker, K. B. E. (2004). Cortical Measures of Anticipation. Jour- 
nal of Psychophysiology, 18, 61-76. https://doi.org/10.1027/0269-8803.18.23.61

Visalberghi, E. (1993). Capuchin Monkeys: A Window into Tool Use in Apes and Humans: In K. R. Gibson, \& T. Ingold (Eds.), Language and Cognition in Human Evolution (pp. 138-150). Cambridge: Cambridge University Press.

Watson, J. B. (1914). Behavior: An Introduction to Comparative Psychology. New York, NY: Henry Holt and Company. https://doi.org/10.1037/10868-000

Wertheimer, M. (1945). Productive Thinking. New York, NY: Harper.

Whitehead, A. N. (1920). The Concept of Nature. Ann Arbor, MI: University of Michigan Press.

Whiten, A., \& Byrne, R. W. (1997). Machiavellian Intelligence II: Extensions and Evaluations. New York, NY: Cambridge University Press. https://doi.org/10.1017/CBO9780511525636

Wilson, E. O. (1975). Sociobiology: The New Synthesis. Cambridge, MA: Harvard University Press. 